\title{
Brassinosteroids increase electron transport and photosynthesis in soybean plants under water deficit
}

\author{
Y.C. PEREIRA*, W.S. RODRIGUES*, E.J.A. LIMA*, L.R. SANTOS*, M.H.L. SILVA**, and \\ A.K.S. LOBATO ${ }^{*+}$ \\ Núcleo de Pesquisa Vegetal Básica e Aplicada, Universidade Federal Rural da Amazônia. Paragominas, Pará, \\ Brazil $^{*}$ \\ Coordenação de Botânica, Museu Paraense Emílio Goeldi, Belém, Pará, Brazil**
}

\begin{abstract}
Drought frequently results in significant losses in agricultural systems, including the soybean yield. Brassinosteroids exhibit multiple actions on essential processes, including chlorophyll fluorescence and gas exchange. Considering that the electron transport rate (ETR) into photosystems can exercise interference on net photosynthetic rate $\left(P_{\mathrm{N}}\right)$, this research aims to determine whether 24-epibrassinolide (EBR) affects electron transport and find out if there is any repercussion on photosynthesis in soybean plants affected by the water deficit. The experiment was performed using a randomized factorial design, with two water conditions (control and water deficit) and three EBR concentrations (0, 50, and 100 nM EBR). The water deficit reduced effective quantum yield of PSII photochemistry, ETR, $P_{\mathrm{N}}$, and water-use efficiency. However, the exogenous application of $100 \mathrm{nM}$ EBR mitigated these negative effects, increasing these variables. EBR reduced the oxidant compounds (superoxide and hydrogen peroxide) and membrane damages (malondialdehyde and electrolyte leakage) in stressed plants. Our study proved that EBR increased ETR and $P_{\mathrm{N}}$ in control and stressed plants, revealing that ETR had a strong relationship with $P_{\mathrm{N}}$. These results suggest that soybean plants with higher values of ETR are more efficient in relation to $P_{\mathrm{N}}$.
\end{abstract}

Additional key words: chlorophyll fluorescence; drought; gas exchange; Glycine max; 24-epibrassinolide.

\section{Introduction}

Soybean is an oleaginous plant with a large capacity to produce grains rich in proteins (Bamji and Corbitt 2017). Soybean are important to human and animal nutrition and are a major source of energy in biofuels (Abdulkhani et al. 2017). Currently, soybean is the most cultivated and consumed legume in the world (Thilakarathna and Raizada 2017) with approximately 314 million tons produced in the 2015/2016 harvest (FAO 2017). The main producer countries of soybean worldwide are the United States of America and Brazil.

Drought is the main abiotic stress on crops because it is the most recurrent, and thus, it frequently promotes significant losses in agricultural systems, thereby reducing food production worldwide (Zhang et al. 2016). Water deficiency is a complex physicochemical process that affects macro- and micromolecules of plant metabolism, which can be more severe at certain stages and provoke irreversible damages, such as protein denaturation and cell death (Bajguz and Hayat 2009, Rajasekar et al. 2016).

Low water availability directly affects metabolism, causing physiological, biochemical, and molecular modifications (Shao et al. 2008). In this content, the water photolysis oxidizes the $\mathrm{H}_{2} \mathrm{O}$ molecule releasing the electrons. Subsequently, these electrons are captured in PSII and transferred to PSI by specific proteins, such as cytochrome $b_{6} / f$ complex and plastocyanin (Rochaix 2011).

Under water deficit, plants normally exhibit negative

Received 23 December 2017; accepted 23 April 2018

${ }^{+}$Corresponding author; phone +5591983089845, e-mail: allanllobato@yahoo.com.br

Abbreviations: BRs - brassinosteroids; Car - carotenoids; Chl - chlorophyll; $C_{\mathrm{i}}-$ intercellular $\mathrm{CO}_{2}$ concentration; $E$ - transpiration rate; EBR - 24-epibrassinolide; EL - electrolyte leakage; ETR - electron transport rate; ETR/ $P_{\mathrm{N}}$ - ratio between the apparent electron-transport rate and net photosynthetic rate; EXC - relative energy excess at the PSII level; $\mathrm{F}_{0}$ - minimal fluorescence yield of the dark-adapted state; $F_{m}-$ maximal fluorescence yield of the dark-adapted state; $F_{v}-$ variable fluorescence; $F_{v} / F_{m}-$ maximal quantum yield of PSII photochemistry; $g_{\mathrm{s}}$ - stomatal conductance to water vapor; LDM - leaf dry matter; MDA - malondialdehyde; $\mathrm{NPQ}$ - nonphotochemical quenching; PEG - polyethylene glycol; $P_{\mathrm{N}}-$ net photosynthetic rate; $P_{\mathrm{N}} / C_{\mathrm{i}}-$ instantaneous carboxylation efficiency; $\mathrm{q}_{\mathrm{P}}$ - photochemical quenching; RDM - root dry matter; ROS - reactive oxygen species; STM - stem dry matter; TDM - total dry matter; WUE - water-use efficiency; $\Phi_{\text {PSII }}$ - effective quantum yield of PSII photochemistry.

Acknowledgements: This research had financial support from Fundação Amazônia de Amparo a Estudos e Pesquisas (FAPESPA/Brazil), Conselho Nacional de Desenvolvimento Científico e Tecnológico (CNPq/Brazil) and Universidade Federal Rural da Amazônia (UFRA/ Brazil) to AKS Lobato. While YC Pereira and WS Rodrigues were supported with scholarships from Programa de Educação Tutorial (PET/Brazil). 
interferences on electron transport rate (Rivas et al. 2016), suggesting that the photosynthetic electron flow is intrinsically depending of the water availability in plant cells (Rutherford and Boussac 2004). Other problem caused by the water deficit is connected to gas exchange; it reduces the stomatal conductance that limits the $\mathrm{CO}_{2}$ influx and consequently decreases the photosynthetic rate (Flexas et al. 2006, Yuan et al. 2016). The water deficit reduces the electron flow and gas exchange, generating oxidative stress due to accumulation of reactive oxygen species (ROS), such as superoxide $\left(\mathrm{O}_{2}^{-}\right)$and hydrogen peroxide $\left(\mathrm{H}_{2} \mathrm{O}_{2}\right)$ (Bajguz and Hayat 2009, Ozkur et al. 2009).

Brassinosteroids (BRs) are substances classified as polyhydroxy steroids (Khalid and Aftab 2016) and are frequently tested in the form of 24-epibrassinolide (EBR). This molecule exhibits multiple actions on essential processes, such as improvement in PSII efficiency (Lima and Lobato 2017), gas exchange (Hu et al. 2013), beneficial repercussions on antioxidant systems (Yuan et al. 2010), and increases in rates of growth and development in plants (Vriet et al. 2013, Wei and Li 2016).

During drought conditions, the EBR application in Capsicum annuum plants mitigated the negative effects on chlorophyll (Chl) fluorescence, more specifically, on the effective quantum yield of PSII photochemistry ( $\left.\Phi_{\mathrm{PSII}}\right)$ (Hu et al. 2013). Study conducted by Anjum et al. (2011) with Zea mays plants treated with EBR revealed beneficial effects on gas exchange, increasing the net photosynthetic rate $\left(P_{\mathrm{N}}\right)$ and stomatal conductance $\left(g_{\mathrm{s}}\right)$. In Hordeum vulgare treated with EBR under effects of polyethylene glycol (PEG)-induced drought stress, applications led to decreases in $\mathrm{H}_{2} \mathrm{O}_{2}$ and malondialdehyde (MDA) accumulations (Gill et al. 2017). Li et al. (2012) described increases in Chl $a$ and $\mathrm{Chl} b$ after EBR treatment in Chorispora bungeana exposed to water deficit.

We hypothesized that the electron flux into photosystems can exercise interference on photosynthesis as the water supply is fundamental to the release of electrons after the water photolysis. The available literature suggests a probable positive effect of the EBR in relation to electron transport. Therefore, the aims of this research were to determine how the EBR acts on electron transport and if there is any repercussion on photosynthesis in soybean plants affected by the water deficit.

\section{Materials and methods}

Location and growth conditions: The experiment was performed at the Campus of Paragominas of the Universidade Federal Rural da Amazônia, Paragominas, Brazil $\left(2^{\circ} 55^{\prime} \mathrm{S}, 47^{\circ} 34^{\prime} \mathrm{W}\right)$. The study was conducted in a greenhouse with the temperature and humidity controlled, under natural light conditions. The minimum, maximum, and median temperatures were 24,34 , and $26.8^{\circ} \mathrm{C}$, respectively. The relative humidity during the experimental period varied between 60 and $80 \%$.

Plants, containers and acclimation: Seeds of Glycine max (L.) Merr. var. M9144RR Monsoy ${ }^{\mathrm{TM}}$ were germinated and grown in $1.2-\mathrm{L}$ pots $(0.15 \mathrm{~m}$ in height, $0.10 \mathrm{~m}$ in diameter $)$ filled with a mixed substrate of sand and vermiculite at a ratio of $3: 1$. The plants were cultivated under semihydroponic conditions, and the pots had one hole in the bottom covered with mesh to maintain the substrate and aerate the roots. Solution absorption was by capillary action, with these pots placed into other containers $(0.15$ $\mathrm{m}$ in height, $0.15 \mathrm{~m}$ in diameter) containing $500 \mathrm{~mL}$ of distilled water for eight days. A modified Hoagland and Arnon (1950) solution was used for nutrients, with the ionic force beginning at 50\% and later modified to $100 \%$ after two days. After one day, the nutritive solution remained at total ionic force.

Experimental design: The experiment was a factorial design with the factors completely randomized, including two water conditions (control and water deficit) and three concentrations of 24-epibrassinolide $(0,50$, and $100 \mathrm{nM}$ EBR). With five replicates for each of the six treatments, a total of 30 experimental units were used in the experiment, with one plant in each unit.

24-epibrassinolide (EBR) preparation and application: Twelve-day-old plants were sprayed with $10 \mathrm{~mL}$ per plant of EBR or Milli-Q water in each application (containing a proportion of ethanol that was equal to that used to prepare the EBR solution) at 5-d intervals until day 27. The 0, 50, and $100 \mathrm{nM}$ EBR (Sigma-Aldrich, USA) solutions were prepared by dissolving the solute in ethanol followed by dilution with Milli-Q water [ethanol:water $(\mathrm{v} / \mathrm{v})=$ 1:10,000] (Ahammed et al. 2013). On day 27 after the experiment was initiated, the plants in the water-deficit treatment were subjected to water restriction.

Plant nutrition and water-deficit treatment: One plant per pot was used to examine plant parameters. The plants received the following macro- and micronutrients contained in the nutrient solution (Sigma-Aldrich, USA): $8.75 \mathrm{mM} \quad \mathrm{KNO}_{3}, 7.5 \mathrm{mM} \quad \mathrm{Ca}\left(\mathrm{NO}_{3}\right)_{2} \cdot 4 \mathrm{H}_{2} \mathrm{O}$, $3.25 \mathrm{mMNH}_{4} \mathrm{H}_{2} \mathrm{PO}_{4}, 1.5 \mathrm{mM} \mathrm{MgSO}_{4} \cdot 7 \mathrm{H}_{2} \mathrm{O}, 62.50 \mu \mathrm{M} \mathrm{KCl}$, $31.25 \mu \mathrm{M} \quad \mathrm{H}_{3} \mathrm{BO}_{3}, 2.50 \mu \mathrm{M} \quad \mathrm{MnSO}_{4} \cdot \mathrm{H}_{2} \mathrm{O}, 2.50 \mu \mathrm{M}$ $\mathrm{ZnSO}_{4} \cdot 7 \mathrm{H}_{2} \mathrm{O}, \quad 0.63 \mu \mathrm{M} \quad \mathrm{CuSO}_{4} \cdot 5 \mathrm{H}_{2} \mathrm{O}, \quad 0.63 \mu \mathrm{M}$ $\mathrm{NaMoO}_{4} \cdot 5 \mathrm{H}_{2} \mathrm{O}$, and $250.0 \mu \mathrm{M}$ NaEDTAFe $\cdot 3 \mathrm{H}_{2} \mathrm{O}$. To simulate the water deficit, the solution was removed completely, the root system was placed in similar pots without water/solution, and the water-deficit treatment was applied within $3 \mathrm{~d}$ (day 27 to 30 after the start of the experiment). During the study, the nutrient solutions were changed at 07:00 h at 3-d intervals, with the $\mathrm{pH}$ adjusted to 5.5 using $\mathrm{HCl}$ or $\mathrm{NaOH}$. On day 30 of the experiment (phenological stage V6), physiological parameters were measured for all plants, and plant tissues were harvested for morphological and biochemical analyses.

Measurement of Chl fluorescence: The minimal fluorescence yield of the dark-adapted state $\left(\mathrm{F}_{0}\right)$, the maximal fluorescence yield of the dark-adapted state $\left(\mathrm{F}_{\mathrm{m}}\right)$, the variable fluorescence $\left(\mathrm{F}_{\mathrm{v}}\right)$ were measured. The maximal quantum yield of PSII photochemistry $\left(\mathrm{F}_{\mathrm{v}} / \mathrm{F}_{\mathrm{m}}\right)$ 
was calculated using the formula $F_{v} / F_{m}=\left(F_{m}-F_{0}\right) / F_{m}$, the effective quantum yield of PSII photochemistry $\left(\Phi_{\text {PSII }}\right)$ was calculated by the formula $\left(\mathrm{F}_{\mathrm{m}},-\mathrm{F}_{\mathrm{s}}\right) / \mathrm{F}_{\mathrm{m}}$. For photochemical quenching coefficient $\left(\mathrm{q}_{\mathrm{P}}\right)$, the formula $\mathrm{q}_{\mathrm{P}}=\left(\mathrm{F}_{\mathrm{m}},-\mathrm{F}_{\mathrm{s}}\right) /\left(\mathrm{F}_{\mathrm{m}}\right.$, $-\mathrm{F}_{0}$ ) was used, while the nonphotochemical quenching (NPQ) was calculated as NPQ $=\left(F_{m}-F_{m}\right) /\left(F_{m}\right)$. The electron transport rate (ETR) was calculated as ETR $=$ $\Phi_{\text {PSII }} \times$ PPFD $\times 0.5 \times 0.84$, where 0.5 is the fraction of the excitation energy to PSII and 0.84 the fraction of incoming light absorbed by the leaves. The relative energy excess at the PSII level (EXC) was calculated by the formula $\mathrm{EXC}=\left(\mathrm{F}_{\mathrm{v}} / \mathrm{F}_{\mathrm{m}}\right)-\left(\Phi_{\mathrm{PSII}}\right) /\left(\mathrm{F}_{\mathrm{v}} / \mathrm{F}_{\mathrm{m}}\right)$, and the ratio between the electron transport rate and the net photosynthetic rate $\left(\mathrm{ETR} / P_{\mathrm{N}}\right)$ were determined using a modulated $\mathrm{Chl}$ fluorometer (OS5p, OptiSciences, USA). Chl fluorescence was measured in fully expanded leaves. Preliminary tests determined the location of the leaf, the part of the leaf, and the time required to obtain the greatest $\mathrm{F}_{\mathrm{v}} / \mathrm{F}_{\mathrm{m}}$ ratio; therefore, the acropetal third of leaves that were in the middle third of the plant and adapted to the dark for $30 \mathrm{~min}$ was used for the evaluation. The intensity and duration of the saturation light pulse were 7,500 $\mu \mathrm{mol}$ (photon) $\mathrm{m}^{-2} \mathrm{~s}^{-1}$ and $0.7 \mathrm{~s}$, respectively.

Evaluation of gas exchange: The net photosynthetic rate $\left(P_{\mathrm{N}}\right)$, transpiration rate $(E)$, stomatal conductance $\left(g_{\mathrm{s}}\right)$, and intercellular $\mathrm{CO}_{2}$ concentration $\left(C_{\mathrm{i}}\right)$ were evaluated using an infrared gas analyser ( $\mathrm{LCPrO}^{+}, \mathrm{ADC}$ BioScientific, UK). These parameters were measured at the adaxial surface of fully expanded leaves located in the middle region of the plant. The water-use efficiency (WUE) was estimated by the formula $P_{\mathrm{N}} / E$, in agreement with Ma et al. (2004). The instantaneous carboxylation efficiency $\left(P_{\mathrm{N}} / C_{\mathrm{i}}\right)$ was calculated using the formula described by Aragão et al. (2012). Gas exchange was evaluated in all plants under constant conditions of $\mathrm{CO}_{2}$ concentration $\left(360 \mu \mathrm{mol} \mathrm{mol}{ }^{-1}\right)$, photosynthetically active radiation $[800 \mu \mathrm{mol}($ photon) $\mathrm{m}^{-2} \mathrm{~s}^{-1}$, air-flow rate $\left(300 \mu \mathrm{mol} \mathrm{s} \mathrm{s}^{-1}\right)$, and temperature $\left(28^{\circ} \mathrm{C}\right)$, between $10: 00$ and $12: 00 \mathrm{~h}$.

Leaf water potential: The leaf water potential $\left(\Psi_{\mathrm{w}}\right)$ was measured using fully expanded leaves located in the middle region of the plant and exposed to light during the period between 11:30 and 12:00 $\mathrm{h}$, which corresponded to the midday potential. To determinate the $\Psi_{\mathrm{w}}$, one leaf per plant and five plants per treatment were measured using an analogue plant moisture system (model 600, PMS Instrument Company, USA). This system is based on the pressure chamber technique (Scholander et al. 1964), and the procedure outlined by Turner (1988) was followed.

Superoxide concentration: To determine $\mathrm{O}_{2}^{-}, 1 \mathrm{~mL}$ of extract was incubated with $30 \mathrm{mM}$ phosphate buffer ( $\mathrm{pH} 7.6$ ) and $0.51 \mathrm{mM}$ hydroxylamine hydrochloride for $20 \mathrm{~min}$ at $25^{\circ} \mathrm{C}$. Then, $17 \mathrm{mM}$ sulphanilamide and $7 \mathrm{mM}$ $\alpha$-naphthylamine were added to the incubation mixture for $20 \mathrm{~min}$ at $25^{\circ} \mathrm{C}$. After the reaction, ethyl ether was added in the identical volume and centrifuged at $3,000 \times g$ for $5 \mathrm{~min}$. The absorbance was measured at $530 \mathrm{~nm}$ (Elstner and Heupel 1976) using spectrophotometer (UV-M51,
Bel Photonics, Italy). $\mathrm{O}_{2}^{-}$concentration was expressed in $\mathrm{nmol} \min ^{-1} \mathrm{~g}^{-1}(\mathrm{FM})$.

Extraction of nonenzymatic compounds: Nonenzymatic compounds $\left(\mathrm{H}_{2} \mathrm{O}_{2}\right.$ and MDA) were extracted as described by (Wu et al. 2006) from leaves, fully expanded and located in the middle region of the plant. Briefly, a mixture for extraction of $\mathrm{H}_{2} \mathrm{O}_{2}$ and MDA was prepared by homogenizing $500 \mathrm{mg}$ of fresh leaf materials in $5 \mathrm{~mL}$ of $5 \%(\mathrm{w} / \mathrm{v})$ trichloroacetic acid. The samples were then centrifuged at $15,000 \times g$ for $15 \mathrm{~min}$ at $3^{\circ} \mathrm{C}$ to collect the supernatant.

Hydrogen peroxide concentration: To measure $\mathrm{H}_{2} \mathrm{O}_{2}$, $200 \mu \mathrm{L}$ of supernatant and $1,800 \mu \mathrm{L}$ of reaction mixture (2.5 $\mathrm{mM}$ potassium phosphate buffer $[\mathrm{pH} 7.0]$ and 500 $\mathrm{mM}$ potassium iodide) were mixed, and the absorbance was measured at $390 \mathrm{~nm}$ (Velikova et al. 2000) using spectrophotometer (UV-M51, Bel Photonics, Italy). $\mathrm{H}_{2} \mathrm{O}_{2}$ concentration was expressed in $\mu \mathrm{mol} \mathrm{g} \mathrm{g}^{-1}(\mathrm{FM})$.

Malondialdehyde concentration: MDA was determined by mixing $500 \mu \mathrm{L}$ of supernatant with $1,000 \mu \mathrm{L}$ of the reaction mixture containing $0.5 \%(\mathrm{w} / \mathrm{v})$ thiobarbituric acid in $20 \%$ trichloroacetic acid. The mixture was incubated in boiling water at $95^{\circ} \mathrm{C}$ for $20 \mathrm{~min}$, with the reaction terminated by placing the reaction container in an ice bath. The samples were centrifuged at $10,000 \times g$ for $10 \mathrm{~min}$, and the absorbance was measured at $532 \mathrm{~nm}$ using a spectrophotometer (UV-M51, Bel Photonics, Italy). The nonspecific absorption at $600 \mathrm{~nm}$ was subtracted from the absorbance data. The MDA-TBA complex (red pigment) amount was calculated based on the method of Cakmak and Horst (1991), with minor modifications and using an extinction coefficient of $155 \mathrm{mM}^{-1} \mathrm{~cm}^{-1}$. MDA concentration was expressed in $\mathrm{nmol}^{-1}(\mathrm{FM})$.

Electrolyte leakage was measured according to the method of Gong et al. (1998) with minor modifications. Fresh tissue $(200 \mathrm{mg})$ was cut into pieces $1 \mathrm{~cm}$ in length and placed in containers with $8 \mathrm{~mL}$ of distilled deionized water. The containers were incubated in a water bath at $40^{\circ} \mathrm{C}$ for $30 \mathrm{~min}$, and the initial electrical conductivity of the medium $\left(\mathrm{EC}_{1}\right)$ was measured. Then, the samples were boiled at $95^{\circ} \mathrm{C}$ for $20 \mathrm{~min}$ to release the electrolytes. After cooling, the final electrical conductivity $\left(\mathrm{EC}_{2}\right)$ was measured (Gong et al. 1998). The percentage of electrolyte leakage was calculated using the formula $\mathrm{EL}(\%)=\left(\mathrm{EC}_{1} /\right.$ $\left.\mathrm{EC}_{2}\right) \times 100$.

Photosynthetic pigments: $\mathrm{Chl}$ and carotenoid (Car) quantifications were performed with $40 \mathrm{mg}$ of fully expanded leaves located in the middle region of the plant. The samples were homogenized in the dark with $8 \mathrm{~mL}$ of $90 \%$ methanol (Nuclear). The homogenate was centrifuged at $6,000 \times g$ for $10 \mathrm{~min}$ at $5^{\circ} \mathrm{C}$. The supernatant was removed, and Chl $a$ and $\mathrm{Chl} b$, Car, and total Chl contents were quantified using a spectrophotometer (UV-M51, Bel Photonics, Italy), according to the methodology of Lichtenthaler and Buschmann (2001). 
Morphological parameters: The growth of roots, stems, and leaves was measured based on constant dry mass after drying in a forced-air ventilation oven at $65^{\circ} \mathrm{C}$.

Data analysis: The data were subjected to two-way analysis of variance $(A N O V A)$, and significant differences between the means were determined using the Scott-Knott's test at a probability level of 5\% (Steel et al. 2006). Standard deviations were calculated for each treatment. Correlation analysis was performed with the Pearson's parametric method. The statistical analyses were performed with Assistat software (Silva and Azevedo 2002).

\section{Results}

EBR improves water potential and PSII efficiency in plants exposed to water deficit: The water deficit promoted significant reduction in $\Psi_{\mathrm{w}}$; however, the water deficit $+100 \mathrm{nM}$ EBR induced an increase of $19 \%$ when compared to the same water condition withoutEBR (Fig. 1). The water deficit caused an increase in values of $\mathrm{F}_{0}$, but the application of $100 \mathrm{nM}$ EBR induced a significant reduction of $29 \%$ when compared to the water deficit without EBR (Fig. 2). For $F_{m}, F_{v}$, and $F_{v} / F_{m}$, these values were reduced under water deficit; however, the concentration of $100 \mathrm{nM}$ of EBR promoted significant increases of 14,44 , and $26 \%$, respectively (Fig. 2).

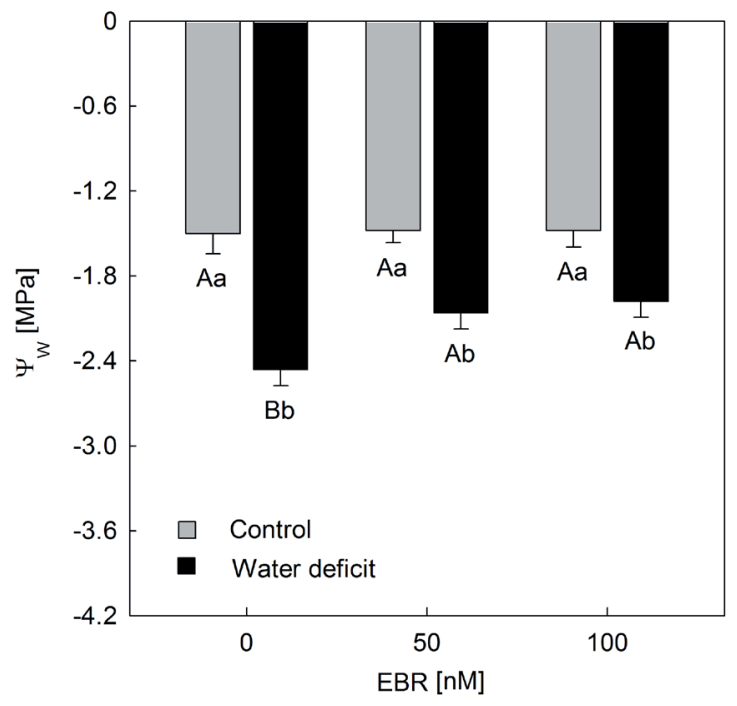

Fig. 1. Leaf water potential in soybean plants sprayed with EBR and exposed to water deficit. Different uppercase letters between EBR concentrations $(0,50$, and $100 \mathrm{nM}$ EBR under equal water conditions) and lowercase letters between water conditions (control and water deficit under equal EBR concentrations) indicate significant differences from the Scott-Knott's test $(P<0.05)$. Means $\pm \mathrm{SD}, n=5$.

The water deficit reduced $\Phi_{\mathrm{PSII}}, \mathrm{q}_{\mathrm{P}}$, and ETR. However, the exogenous application of EBR promoted increases of 50,6 , and $44 \%$ in these variables, respectively, in plants with $100 \mathrm{nM}$ EBR when compared to plants in the waterdeficit treatment without EBR (Table 1). For NPQ, EXC, and $\mathrm{ETR} / P_{\mathrm{N}}$, the stress conditions caused increases in these variables; however, under the EBR treatment, these variables were significantly reduced. The values of NPQ and ETR $/ P_{\mathrm{N}}$ suffered declines in the water deficit +100 nM EBR treatment (22 and $73 \%$, respectively). For EXC, the lowest level was under the water deficit $+50 \mathrm{nM}$ EBR treatment (20\%) when compared to equal water conditions and $0 \mathrm{nM} \mathrm{EBR}$.

Plants exposed to water deficit + EBR increased their gas exchange: Plants under water deficit presented decreases in $P_{\mathrm{N}}, E, g_{\mathrm{s}}, \mathrm{WUE}$, and $P_{\mathrm{N}} / C_{\mathrm{i}}$, but $100 \mathrm{nM}$ EBR induced increases of $436,45,240,273$, and $650 \%$, respectively (Table 2). However, the $C_{\mathrm{i}}$ were higher in the plants under water deficit and values were reduced by EBR utilization. The concentration of $100 \mathrm{nM}$ decreased the value of $C_{\mathrm{i}}$ by $23 \%$ when compared to plants under the water deficit without EBR. The correlation analysis revealed that there is a strong and positive relationship between ETR and $P_{\mathrm{N}}$ $(r=0.97 ; P<0.01)$ (Fig. 3).

EBR reduced the oxidant compounds and membrane damages in stressed plants: The water deficit promoted increases in $\mathrm{O}_{2}^{-}, \mathrm{H}_{2} \mathrm{O}_{2}, \mathrm{MDA}$, and $\mathrm{EL}$ (Fig. 4). However, EBR application significantly minimized these variables with plants exposed to $100 \mathrm{nM}$ EBR exhibiting reductions of $27,47,42$, and $17 \%$, respectively, when compared to plants after the treatment under water deficit without EBR application.

Minor stress on photosynthetic pigments due to steroid action: The water deficit induced significant decreases in Chl $a, \mathrm{Chl} b$, total Chl, and Car contents. However, plants sprayed with $100 \mathrm{nM}$ EBR exhibited increases by 45 , 106,56 , and $80 \%$ for these variables, respectively, when compared to plants under the water deficit $+0 \mathrm{nM}$ EBR (Table 3). The ratio $\mathrm{Chl} a / b$ and ratio total $\mathrm{Chl} / \mathrm{Car}$ showed increases induced by the water deficit that were minimized after the use of EBR.

EBR attenuated the impact produced by the water deficit on growth: Plants subjected to water deficit showed a reduction in LDM, but the application of EBR promoted the increase of LDM, SDM, and TDM, in plants treated with $100 \mathrm{nM}$ EBR showing increases of 13, 11, and $8 \%$, respectively (Fig. 5). In relation to the water-deficit treatment, the concentration of $50 \mathrm{nM}$ caused an increase of $10 \%$ in RDM compared with plants under the water deficit without EBR.

\section{Discussion}

The benefit found on $\Psi_{\mathrm{W}}$ in plants subjected to water deficit and treated with EBR suggests that the EBR improves the process of osmotic adjustment (Chaves and Seraphin 2001). This mechanism is fundamental to plants in order to complete important processes such as turgescence maintenance and regulation of stomatal opening in plants under conditions of low water availability (Silveira et al. 2009). Zhang et al. (2008) studied Glycine max exposed 


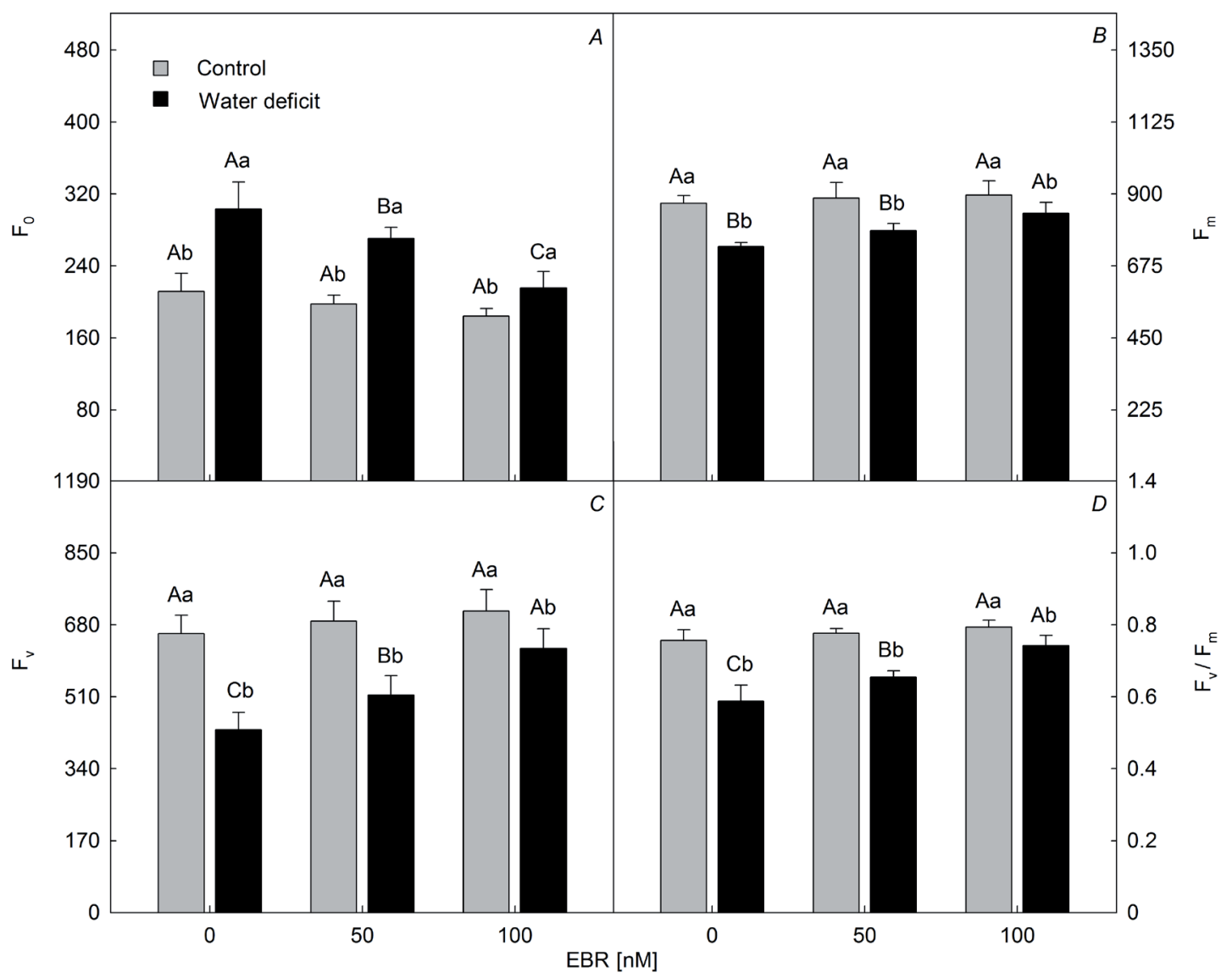

Fig. 2. Minimal fluorescence yield of the dark-adapted state $\left(\mathrm{F}_{0} ; A\right)$, maximal fluorescence yield of the dark-adapted state $\left(\mathrm{F}_{\mathrm{m}} ; B\right)$, variable fluorescence $\left(\mathrm{F}_{\mathrm{v}} ; C\right)$, and maximal quantum yield of PSII photochemistry $\left(\mathrm{F}_{\mathrm{v}} / \mathrm{F}_{\mathrm{m}} ; D\right)$ in soybean plants sprayed with EBR and exposed to water deficit. Different uppercase letters between EBR concentrations $(0,50$, and $100 \mathrm{nM}$ EBR under equal water condition) and lowercase letters between water conditions (control and water deficit under equal EBR concentrations) indicate significant differences from the Scott-Knott's test $(P<0.05)$. Means $\pm \mathrm{SD}, n=5$.

Table 1. Chlorophyll fluorescence in soybean plants splayed with EBR and exposed to water deficit. $\Phi_{\mathrm{PSII}}-$ effective quantum yield of PSII photochemistry; $\mathrm{q}_{\mathrm{P}}$ - photochemical quenching coefficient; NPQ - nonphotochemical quenching; ETR - electron transport rate; EXC - relative energy excess at the PSII level; ETR $/ P_{\mathrm{N}}$ - ratio between the electron transport rate and net photosynthetic rate. Columns with different uppercase letters between EBR concentrations $(0,50$, and $100 \mathrm{nM}$ EBR under equal water condition) and lowercase letters between water conditions (control and water deficit under equal EBR concentration) indicate significant differences from the Scott-Knott's test $(P<0.05)$. Means $\pm \mathrm{SD}, n=5$.

\begin{tabular}{llllllll}
\hline $\begin{array}{l}\text { Water } \\
\text { condition }\end{array}$ & EBR $[\mathrm{nM}]$ & $\Phi_{\mathrm{PSII}}$ & $\mathrm{q}_{\mathrm{P}}$ & $\mathrm{NPQ}$ & $\mathrm{ETR}\left[\mu \mathrm{mol} \mathrm{m}^{-2} \mathrm{~s}^{-1}\right]$ & $\mathrm{EXC}\left[\mu \mathrm{mol} \mathrm{m}{ }^{-2} \mathrm{~s}^{-1}\right]$ & $\mathrm{ETR} / \mathrm{P}_{\mathrm{N}}$ \\
\hline Control & 0 & $0.55 \pm 0.03^{\mathrm{Aa}}$ & $0.81 \pm 0.05^{\mathrm{Aa}}$ & $0.59 \pm 0.05^{\mathrm{Ab}}$ & $78.9 \pm 1.8^{\mathrm{Ba}}$ & $0.27 \pm 0.03^{\mathrm{Ab}}$ & $5.37 \pm 0.15^{\mathrm{Ab}}$ \\
Control & 50 & $0.57 \pm 0.03^{\mathrm{Aa}}$ & $0.83 \pm 0.08^{\mathrm{Aa}}$ & $0.54 \pm 0.05^{\mathrm{Ab}}$ & $84.0 \pm 2.7^{\mathrm{Aa}}$ & $0.26 \pm 0.02^{\mathrm{Ab}}$ & $5.18 \pm 0.30^{\mathrm{Ab}}$ \\
Control & 100 & $0.59 \pm 0.02^{\mathrm{Aa}}$ & $0.88 \pm 0.06^{\mathrm{Aa}}$ & $0.53 \pm 0.04^{\mathrm{Ab}}$ & $86.1 \pm 3.0^{\mathrm{Aa}}$ & $0.26 \pm 0.01^{\mathrm{Ab}}$ & $5.20 \pm 0.23^{\mathrm{Ab}}$ \\
Water deficit & 0 & $0.28 \pm 0.02^{\mathrm{Cb}}$ & $0.64 \pm 0.06^{\mathrm{Ab}}$ & $3.01 \pm 0.03^{\mathrm{Aa}}$ & $41.4 \pm 2.2^{\mathrm{Cb}}$ & $0.54 \pm 0.02^{\mathrm{Aa}}$ & $52.05 \pm 2.81^{\mathrm{Aa}}$ \\
Water deficit & 50 & $0.37 \pm 0.01^{\mathrm{Bb}}$ & $0.67 \pm 0.04^{\mathrm{Ab}}$ & $2.50 \pm 0.01^{\mathrm{Ba}}$ & $54.4 \pm 1.6^{\mathrm{Bb}}$ & $0.43 \pm 0.02^{\mathrm{Ba}}$ & $18.39 \pm 1.57^{\mathrm{Ba}}$ \\
Water deficit & 100 & $0.42 \pm 0.02^{\mathrm{Ab}}$ & $0.68 \pm 0.02^{\mathrm{Ab}}$ & $2.34 \pm 0.11^{\mathrm{Ca}}$ & $59.5 \pm 2.7^{\mathrm{Ab}}$ & $0.46 \pm 0.03^{\mathrm{Ba}}$ & $13.87 \pm 0.81^{\mathrm{Ba}}$ \\
\hline
\end{tabular}

to water deficit and reported that the application of $0.1 \mathrm{mg} \mathrm{L} \mathrm{L}^{-1}$ brassinolide promoted an increase of $21 \%$ in $\Psi_{\mathrm{W}}$ when compared to plants in equal water conditions without the addition of EBR.

Plants exposed to the water deficit + EBR treatment showed increases in $F_{v}$ and $F_{v} / F_{m}$. The increase in $F_{v}$ is explained by the maximization of $\mathrm{F}_{\mathrm{m}}$ and reduction in
$\mathrm{F}_{0}$, as verified in this study. In addition, the increase of $\mathrm{F}_{\mathrm{v}} / \mathrm{F}_{\mathrm{m}}$ in plants treated with EBR confirms the attenuation of the photoinhibitory damages promoted by the water deficit on PSII reaction centres (Tukaj et al. 2007). Wu et al. (2014) evaluated the effects of four concentrations of EBR on seedlings of Solanum melongena exposed to elevated temperatures and reported a reduction in $\mathrm{F}_{0}$ 
Table 2. Gas exchange in soybean plants sprayed with EBR and exposed to water deficit. $P_{\mathrm{N}}-$ net photosynthetic rate; $E$ - transpiration rate; $g_{\mathrm{s}}$ - stomatal conductance; $C_{\mathrm{i}}$ - intercellular $\mathrm{CO}_{2}$ concentration; WUE - water-use efficiency; $P_{\mathrm{N}} / C_{\mathrm{i}}-$ carboxylation instantaneous efficiency. Columns with different uppercase letters between EBR concentrations (0,50, and $100 \mathrm{nM}$ EBR under equal water conditions) and lowercase letters between water conditions (control and water deficit under equal EBR concentration) indicate significant differences from the Scott-Knott's test $(P<0.05)$. Means $\pm \mathrm{SD}, n=5$.

\begin{tabular}{|c|c|c|c|c|c|c|c|}
\hline Water condition & $\mathrm{EBR}(\mathrm{nM})$ & $P_{\mathrm{N}}\left[\mu \mathrm{mol} \mathrm{m}{ }^{-2} \mathrm{~s}^{-1}\right]$ & $E\left[\mathrm{mmol} \mathrm{m}^{-2} \mathrm{~s}^{-1}\right]$ & $g_{\mathrm{s}}\left[\mathrm{mol} \mathrm{m}{ }^{-2} \mathrm{~s}^{-1}\right]$ & $C_{\mathrm{i}}\left[\mu \mathrm{mol} \mathrm{mol}{ }^{-1}\right]$ & $\begin{array}{l}\text { WUE } \\
{\left[\mu \mathrm{mol} \mathrm{mmol}{ }^{-1}\right]}\end{array}$ & $\begin{array}{l}P_{\mathrm{N}} / C_{\mathrm{i}} \\
{\left[\mu \mathrm{mol} \mathrm{m}{ }^{-2} \mathrm{~s}^{-1} \mathrm{~Pa}^{-1}\right]}\end{array}$ \\
\hline Control & 0 & $15.05 \pm 0.33^{\mathrm{Ba}}$ & $3.04 \pm 0.21^{\mathrm{Aa}}$ & $0.28 \pm 0.02^{\mathrm{Ba}}$ & $262 \pm 07^{\mathrm{Ba}}$ & $4.96 \pm 0.14^{\mathrm{Bb}}$ & $0.060 \pm 0.008^{\mathrm{Ba}}$ \\
\hline Control & 50 & $16.23 \pm 0.57^{\mathrm{Aa}}$ & $3.08 \pm 0.29^{\mathrm{Aa}}$ & $0.31 \pm 0.01^{\mathrm{Aa}}$ & $242 \pm 08^{\mathrm{Aa}}$ & $5.31 \pm 0.11^{\mathrm{Aa}}$ & $0.067 \pm 0.006^{\mathrm{Aa}}$ \\
\hline Control & 100 & $16.58 \pm 0.42^{\mathrm{Aa}}$ & $3.09 \pm 0.02^{\mathrm{Aa}}$ & $0.30 \pm 0.02^{\mathrm{Aa}}$ & $236 \pm 04^{\mathrm{Aa}}$ & $5.36 \pm 0.12^{\mathrm{Aa}}$ & $0.070 \pm 0.007^{\mathrm{Aa}}$ \\
\hline Water deficit & 0 & $0.80 \pm 0.03^{\mathrm{Cb}}$ & $0.92 \pm 0.09^{\mathrm{Bb}}$ & $0.05 \pm 0.01^{\mathrm{Cb}}$ & $350 \pm 21^{\mathrm{Cb}}$ & $0.87 \pm 0.05^{\mathrm{Cb}}$ & $0.002 \pm 0.002^{\mathrm{Cb}}$ \\
\hline Water deficit & 50 & $2.98 \pm 0.30^{\mathrm{Bb}}$ & $1.09 \pm 0.10^{\mathrm{Bb}}$ & $0.08 \pm 0.01^{\mathrm{Bb}}$ & $310 \pm 11^{\mathrm{Bb}}$ & $2.75 \pm 0.21^{\mathrm{Bb}}$ & $0.010 \pm 0.001^{\mathrm{Bb}}$ \\
\hline Water deficit & 100 & $4.29 \pm 0.21^{\mathrm{Ab}}$ & $1.33 \pm 0.07^{\mathrm{Ab}}$ & $0.17 \pm 0.01^{\mathrm{Ab}}$ & $269 \pm 19^{\mathrm{Ab}}$ & $3.25 \pm 0.20^{\mathrm{Ab}}$ & $0.015 \pm 0.001^{\mathrm{Ab}}$ \\
\hline
\end{tabular}

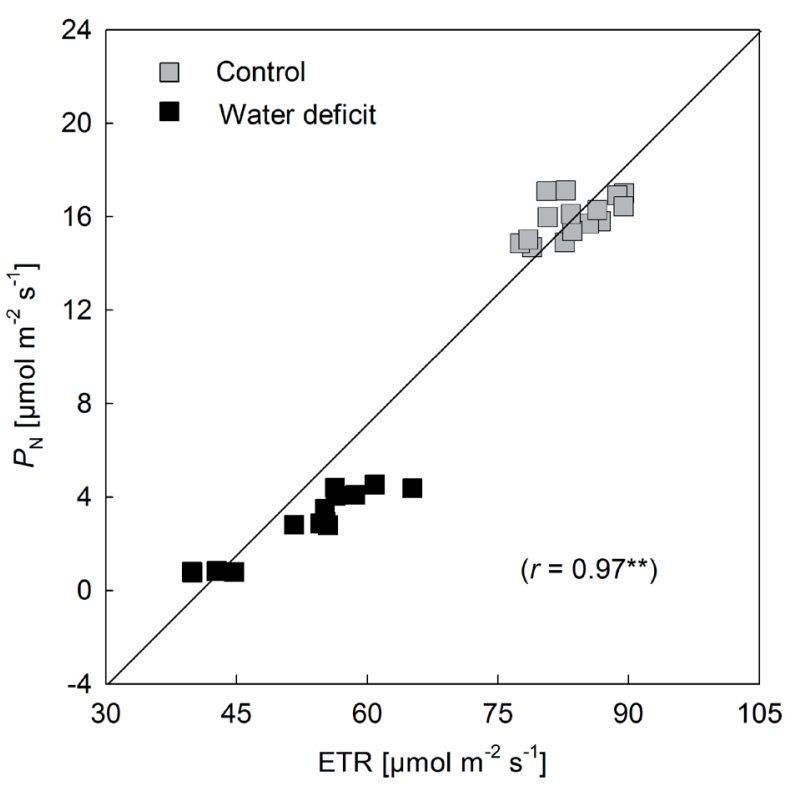

Fig. 3. Relationship between electron transport rate (ETR) and net photosynthetic rate $\left(P_{\mathrm{N}}\right)$ in soybean plants sprayed with EBR and exposed to water deficit. Asterisks $\left({ }^{* *}\right)$ indicate the significance at 0.01 probability level.

after the use of $0.4 \mu \mathrm{M}$ EBR. Corroborating our results, Souza et al. (2004) studying the Chl fluorescence in Vigna unguiculata exposed to water deficit presented an increase in $\mathrm{F}_{0}$ and a reduction in $\mathrm{F}_{\mathrm{m}}$ when compared to the control plants. Wang et al. (2015) examined Vitis vinifera treated with EBR and submitted to water deficit and reported that the exogenous application of EBR promoted an increase in $\mathrm{F}_{\mathrm{v}} / \mathrm{F}_{\mathrm{m}}$.

The exogenous application of EBR promoted increases in $\Phi_{\text {PSII }}, q_{P}$, and ETR. This result linked to $\Phi_{\text {PSII }}$ clearly reveals a higher efficiency of the reaction centres aiming the capture of excited light energy ( $\mathrm{Yu}$ et al. 2004). The increases in $\mathrm{q}_{\mathrm{P}}$ and ETR promoted by the EBR reveals the positive interference on the activation of the PSII reaction centres, inducing the oxidation of $\mathrm{Q}_{\mathrm{A}}$, the primary quinone molecule responsible for receiving and transferring electrons between PSII and PSI (Maxwell and Johnson 2000, Singh and Prasad 2014, Jia et al. 2015). Li et al. (2015) found benefits for PSII after EBR application in seedlings of Capsicum annuum subjected to oxidative stress by low temperature, in which plants exposed to low temperature $+0.1 \mu \mathrm{M}$ EBR exhibited significant increases of 13.2 and $5.6 \%$ in $\Phi_{\mathrm{PSII}}$ and $\mathrm{q}_{\mathrm{P}}$, respectively, compared to the treatment under low temperature without EBR.

In plants under water deficit, the application of EBR promoted reductions in EXC, NPQ, and ETR $/ P_{\mathrm{N}}$. The decrease in EXC was due to a reduction in NPQ because the EBR reduced the loss of photons mainly in the form of heat, through the optimization in the use of light energy into photochemical processes (Zhang et al. 2015). The reduction in ETR $/ P_{\mathrm{N}}$ suggests lesser distribution of electrons to alternative drains, such as photorespiration and the Mehler reaction (Fang et al. 2011, Silva et al. 2012). Similarly, to results described in this study, Lima and Lobato (2017) working with Vigna unguiculata under water deficit observed that the application of $100 \mathrm{nM}$ EBR induced significant reductions of 19,30 , and $12 \%$ in the variables EXC, NPQ, and ETR $/ P_{\mathrm{N}}$, respectively, when compared to plants under equal water conditions without EBR.

Plants exposed to the water deficit + EBR treatment presented increases in $P_{\mathrm{N}}$ and $P_{\mathrm{N}} / C_{\mathrm{i}}$. The increase of $P_{\mathrm{N}}$ and decrease of $C_{\mathrm{i}}$ is due to EBR increasing the efficiency of Rubisco, an enzyme responsible for the carboxylation of $\mathrm{CO}_{2}$ during the photosynthetic process (Yu et al. 2004). Our study proved that EBR increased ETR and $P_{\mathrm{N}}$ in control and stressed plants, revealing that ETR had a strong relationship with $P_{\mathrm{N}}$ as evidenced by a strong correlation $(r=0.97)$. These results suggest that soybean plants with higher values of ETR are more efficient in relation to $P_{\mathrm{N}}$, and new research is necessary to evaluate the effects of EBR on components of production. Xia et al. (2009) reported a decrease of $C_{\mathrm{i}}$ in plants submitted to EBR application in a study on the roles of EBR and brassinazole linked to synthesis and activation of enzymes of the photosynthetic apparatus in Cucumis sativus. Hu et al. (2013) examined Capsicum annuum under conditions of $45 \%$ water content in the soil and observed that the application of $0.01 \mathrm{mg} \mathrm{L}^{-1}$ EBR attenuated the negative effects on $P_{\mathrm{N}}$, increasing the $\mathrm{CO}_{2}$ assimilation and efficiency of light use.

The EBR also provided increases in $g_{\text {s }}$ and $E$. The attenuation of the water deficit on $\Psi_{\mathrm{W}}$ induced beneficial repercussion on these variables $\left(g_{\mathrm{s}}\right.$ and $E$ ). Plants under water deficit frequently decrease the stomatal opening to lower the water loss through the transpiration process (Martineau et al. 2017). Singh and Reddy (2011) evaluated 


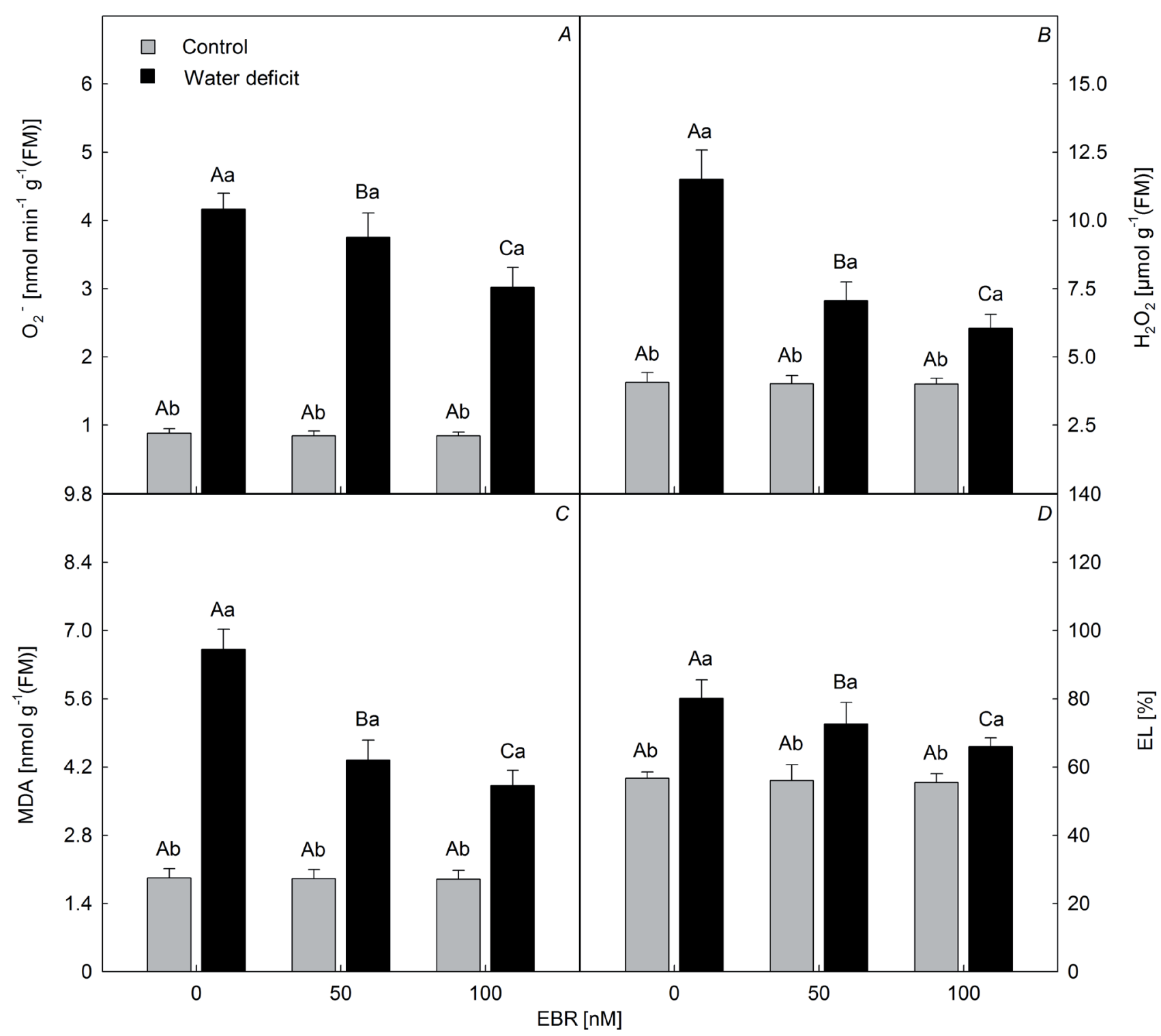

Fig. 4. Superoxide $\left(\mathrm{O}_{2}^{-} ; A\right)$, hydrogen peroxide $\left(\mathrm{H}_{2} \mathrm{O}_{2} ; B\right)$, malondialdehyde (MDA; $\left.C\right)$, and electrolyte leakage (EL; $\left.D\right)$ in soybean plants sprayed with EBR and exposed to water deficit. Different uppercase letters between EBR concentrations $(0,50$, and $100 \mathrm{nM}$ EBR under equal water condition) and lowercase letters between water conditions (control and water deficit under equal EBR concentrations) indicate significant differences from the Scott-Knott's test $(P<0.05)$. Means $\pm \mathrm{SD}, n=5$.

the dynamics of photosynthesis and the WUE in 15 genotypes of Vigna unguiculata under water deficit and described an exponential relationship between $g_{\text {s }}$ and $E$. In addition, Lima and Lobato (2017) found that $g_{\text {s }}$ and $E$ suffered significant reductions in Vigna unguiculata under water deficit; however, the exogenous application of 100 $\mathrm{nM}$ of EBR caused increases of 24 and $33 \%$ in these variables, respectively.

The increase in $P_{\mathrm{N}}$ positively influenced the WUE in Glycine max submitted to the water deficit + EBR treatment. Fariduddin et al. (2009), investigating the application of $0.01 \mu \mathrm{M}$ of 28-homobrassinolide on the gas exchange and the antioxidant system in Brassica juncea subjected to water deficit, obtained an increase of $53 \%$ in
WUE when compared to non-pulverized plants.

The EBR application mitigated the effects caused by the water deficit on $\mathrm{O}_{2}^{-}$and $\mathrm{H}_{2} \mathrm{O}_{2}$ due to the minimization of NPQ and EXC. Excess energy and inadequate electron flow often result in the overproduction of reactive oxygen species (ROS) such as $\mathrm{O}_{2}^{-}$and $\mathrm{H}_{2} \mathrm{O}_{2}$ (Lawlor and Tezara 2009). Yi et al. (2016) studying the mechanisms of photosynthetic recovery in leaves of Gossypium herbaceum under water deficit and rehydration also obtained increases in $\mathrm{O}_{2}^{-}$and $\mathrm{H}_{2} \mathrm{O}_{2}$ concentrations. $\mathrm{Wu}$ et al. (2014) investigating the effects of high temperature and five concentrations of EBR on the growth of Solanum melongena showed that the use of EBR at $0.1 \mu \mathrm{M}$ was more effective, reducing $\mathrm{O}_{2}^{-}$and $\mathrm{H}_{2} \mathrm{O}_{2}$ contents by 32 and 
Table 3. Photosynthetic pigments in soybean plants splayed with EBR and exposed to water deficit. Chl - chlorophyll; Car - carotenoids. Columns with different uppercase letters between EBR concentrations $(0,50$, and $100 \mathrm{nM}$ EBR under equal water conditions) and lowercase letters between water conditions (control and water deficit under equal EBR concentration) indicate significant differences from the Scott-Knott 's test $(P<0.05)$. Means $\pm \mathrm{SD}, n=5$.

\begin{tabular}{llllllll}
\hline $\begin{array}{l}\text { Water } \\
\text { condition }\end{array}$ & $\begin{array}{l}\text { EBR } \\
{[\mathrm{nM}]}\end{array}$ & $\begin{array}{l}\mathrm{l} \text { Chl } a \\
{\left[\mathrm{mg} \mathrm{g}^{-1}(\mathrm{FM})\right]}\end{array}$ & $\begin{array}{l}\mathrm{Chl} b \\
{\left[\mathrm{mg} \mathrm{g}^{-1}(\mathrm{FM})\right.}\end{array}$ & $\begin{array}{l}\text { Total Chl } \\
{\left[\mathrm{mg} \mathrm{g}^{-1}(\mathrm{FM})\right]}\end{array}$ & Car $\left[\mathrm{mg} \mathrm{g}^{-1}(\mathrm{FM})\right]$ & Chl $a /$ Chl $b$ & Total Chl/Car \\
\hline Control & 0 & $11.16 \pm 0.13^{\mathrm{Aa}}$ & $6.16 \pm 0.38^{\mathrm{Ba}}$ & $17.32 \pm 0.63^{\mathrm{Aa}}$ & $2.92 \pm 0.13^{\mathrm{Aa}}$ & $1.83 \pm 0.17^{\mathrm{Ab}}$ & $5.95 \pm 0.27^{\mathrm{Ab}}$ \\
Control & 50 & $11.16 \pm 0.79^{\mathrm{Aa}}$ & $6.28 \pm 0.22^{\mathrm{Ba}}$ & $17.44 \pm 1.21^{\mathrm{Aa}}$ & $3.02 \pm 0.12^{\mathrm{Aa}}$ & $1.72 \pm 0.11^{\mathrm{Ab}}$ & $5.78 \pm 0.43^{\mathrm{Ab}}$ \\
Control & 100 & $11.22 \pm 0.91^{\mathrm{Aa}}$ & $6.98 \pm 0.27^{\mathrm{Aa}}$ & $18.21 \pm 1.01^{\mathrm{Aa}}$ & $3.16 \pm 0.31^{\mathrm{Aa}}$ & $1.62 \pm 0.12^{\mathrm{Ab}}$ & $5.77 \pm 0.34^{\mathrm{Ab}}$ \\
Water deficit & 0 & $6.64 \pm 0.48^{\mathrm{Bb}}$ & $2.08 \pm 0.10^{\mathrm{Cb}}$ & $8.72 \pm 0.53^{\mathrm{Cb}}$ & $0.95 \pm 0.10^{\mathrm{Cb}}$ & $3.20 \pm 0.09^{\mathrm{Aa}}$ & $9.18 \pm 0.46^{\mathrm{Aa}}$ \\
Water deficit & 50 & $8.89 \pm 0.58^{\mathrm{Ab}}$ & $3.12 \pm 0.30^{\mathrm{Bb}}$ & $12.00 \pm 0.52^{\mathrm{Bb}}$ & $1.37 \pm 0.10^{\mathrm{Bb}}$ & $2.88 \pm 0.12^{\mathrm{Ba}}$ & $8.81 \pm 0.25^{\mathrm{Aa}}$ \\
Water deficit & 100 & $9.31 \pm 0.92^{\mathrm{Ab}}$ & $4.29 \pm 0.34^{\mathrm{Ab}}$ & $13.60 \pm 0.60^{\mathrm{Ab}}$ & $1.71 \pm 0.10^{\mathrm{Ab}}$ & $2.19 \pm 0.18^{\mathrm{Ca}}$ & $7.98 \pm 0.38^{\mathrm{Ba}}$ \\
\hline
\end{tabular}

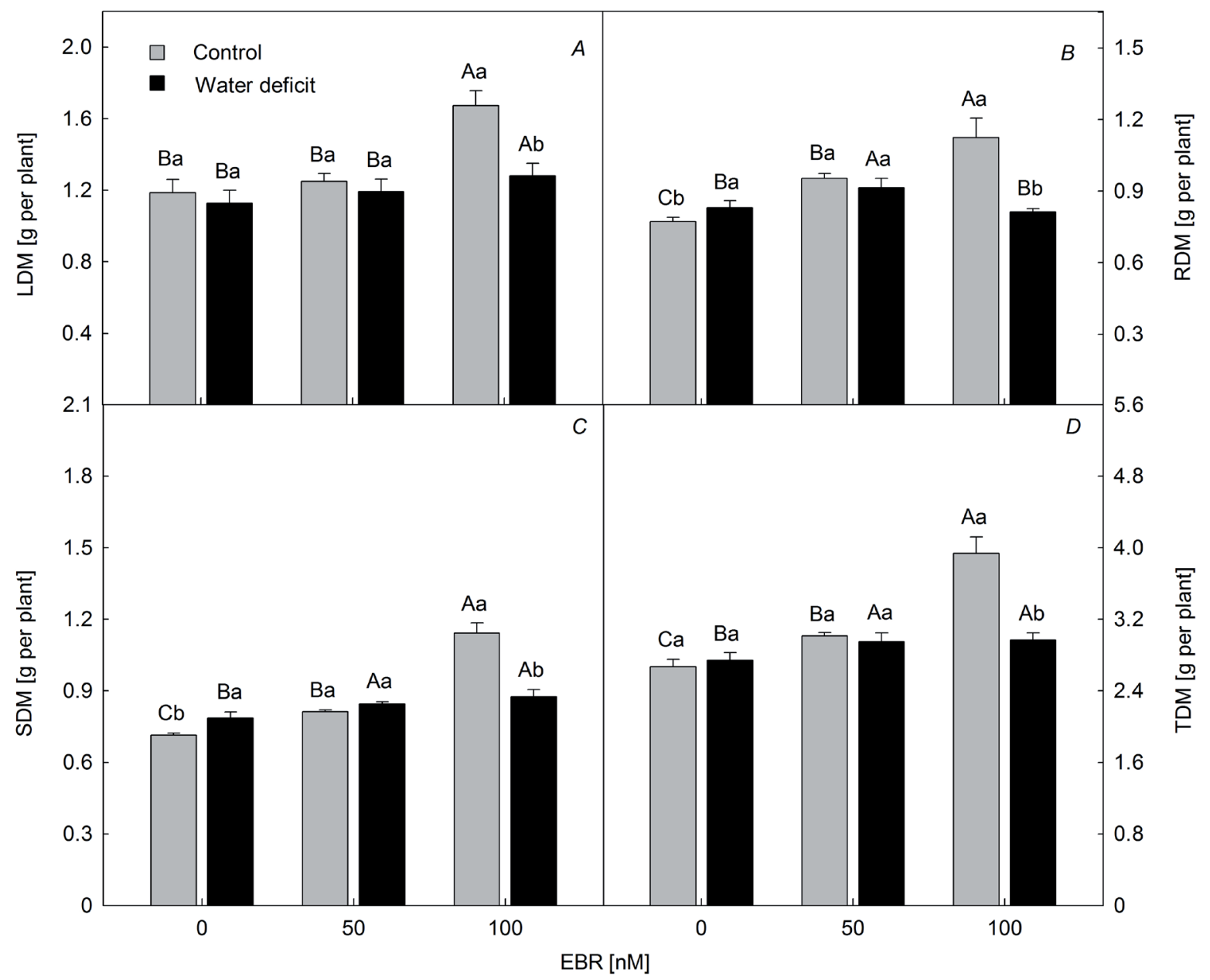

Fig. 5. Leaf dry matter (LDM; $A$ ), root dry matter (RDM; $B)$, stem dry matter (SDM; $C$ ), and total dry matter (TDM; $D)$ in soybean plants sprayed with EBR and exposed to water deficit. Different uppercase letters between EBR concentrations $(0,50$, and $100 \mathrm{nM}$ EBR under equal water condition) and lowercase letters between water conditions (control and water deficit under equal EBR concentrations) indicate significant differences from the Scott-Knott's test $(\mathrm{P}<0.05)$. Means $\pm \mathrm{SD}, \mathrm{n}=5$.

$41 \%$, respectively, compared to non-sprayed plants.

Plants submitted to the water deficit + EBR treatment showed reductions in MDA and EL provided by the lower production of $\mathrm{O}_{2}^{-}$and $\mathrm{H}_{2} \mathrm{O}_{2}$. These compounds are extremely toxic and in excess cause lipid peroxidation, inducing damages to cellular membranes and increases in electrolyte leakage (Gill and Tuteja 2010). Behnamnia et al. (2009b) studying the effects of three EBR concentrations in Lycopersicon esculentum exposed to five days under water deficit reported that this steroid mitigated the effects of water deficit on MDA. Li et al. (2012) evaluating the EBR benefits in Chorispora bungeana under water deficit observed that the concentration of $0.1 \mu \mathrm{M}$ EBR promoted significant reduction in EL. 
The EBR mitigated the negative effects on the ratio of Chl $a / b$ and the ratio of total $\mathrm{Chl} / \mathrm{Car}$ in plants under conditions of water deficit. Plants sprayed with $100 \mathrm{nM}$ EBR and exposed to the water deficit exhibited an increase $(106 \%)$ in Chl $b$. These increases verified in Chl $b$ contents induced by EBR revealed minor photooxidative stress in chloroplasts because the $\mathrm{Chl} b$ is a molecule essentially linked to LHCII (Fleta-Soriano and Munné-Bosch 2016). Dobrikova et al. (2014), studying Pisum sativum exposed to stress by UV-B irradiation and sprayed with $0.1 \mathrm{mg} \mathrm{L}^{-1}$ EBR, observed a reduction of $11.6 \%$ in the ratio $\mathrm{Chl} a / b$ after 48-h exposure to irradiation UV-B.

Plants treated with EBR presented attenuation of the impact produced by the water deficit on LDM, RDM, STM, and TDM. Responses related to $\Phi_{\mathrm{PSII}}, \mathrm{ETR}$, and $P_{\mathrm{N}}$ promoted benefits on growth parameters, previously detected after the EBR utilization. The growth is directly dependent on $P_{\mathrm{N}}$ and $\Phi_{\mathrm{PSII}}$; the maximization of the plant dry matter is associated with the increases of the assimilation of $\mathrm{CO}_{2}$ and PSII efficiency (Barbosa et al. 2015). Liu et al. (2016) examined the effects of the water deficit on the photosynthetic characteristics and dry matter of two genotypes of Triticum aestivum at different water regimes, and they reported that moderate or severe water stress promoted a reduction in leaf and stem matters in both cultivars. However, (Behnamnia et al. 2009a) evaluated the effects of EBR and water deficits on Lycopersicon esculentum and detected an increase of $70 \%$ in shoot dry matter of plants under water deficit $+1 \mu \mathrm{M}$ EBR, corroborating the results of this study.

Our results clearly demonstrated the inferences promoted by the water deficit on photosynthetic apparatus, reducing the effective quantum yield of PSII photochemistry, ETR, $P_{\mathrm{N}}$, and water-use efficiency. However, the exogenous application of $100 \mathrm{nM}$ EBR mitigated these negative effects, increasing these variables. EBR reduced the oxidant compounds (superoxide and hydrogen peroxide) and membrane damages (malondialdehyde and electrolyte leakage) in stressed plants. Our study proved that EBR increased ETR and $P_{\mathrm{N}}$ in control and stressed plants, revealing that ETR had a strong relationship with $P_{\mathrm{N}}$. These results suggest that soybean plants with higher values of ETR are more efficient in relation to $P_{\mathrm{N}}$.

\section{References}

Abdulkhani A., Alizadeh P., Hedjazi S. et al.: Potential of Soya as a raw material for a whole crop biorefinery. - Renew. Sust. Energ. Rev. 75: 1269-1280, 2017.

Ahammed G.J., Choudhary S.P., Chen S. et al.: Role of brassinosteroids in alleviation of phenanthrene-cadmium co-contamination-induced photosynthetic inhibition and oxidative stress in tomato. - J. Exp. Bot. 64: 199-213, 2013.

Anjum S.A., Wang L.C., Farooq M. et al.: Brassinolide application improves the drought tolerance in maize through modulation of enzymatic antioxidants and leaf gas exchange. - J. Agron. Crop Sci. 197: 177-185, 2011.

Aragão R.M., Silva E.N., Vieira C.F. et al.: High supply of $\mathrm{NO}_{3}$ - mitigates salinity effects through an enhancement in the efficiency of photosystem II and $\mathrm{CO}_{2}$ assimilation in Jatropha curcas plants. - Acta Physiol. Plant. 34: 2135-2143, 2012.
Bajguz A., Hayat S.: Effects of brassinosteroids on the plant responses to environmental stresses. - Plant Physiol. Bioch. 47: 1-8, 2009.

Bamji S.F., Corbitt C.: Glyceollins: Soybean phytoalexins that exhibit a wide range of health-promoting effects. - J. Funct. Foods 34: 98-105, 2017.

Barbosa A.M, Guidorizi K.A., Catuchi T.A. et al.: Biomass and bioenergy partitioning of sugarcane plants under water deficit. - Acta Physiol. Plant. 37: 142, 2015.

Behnamnia M., Kalantari K.M., Rezanejad F.: Exogenous application of brassinosteroid alleviates drought-induced oxidative stress in Lycopersicon esculentum L. - Gen. Appl. Plant Physiol. 35: 22-34, 2009a.

Behnamnia M., Kalantari K.M., Ziaie J.: The effects of brassinosteroid on the induction of biochemical changes in Lycopersicon esculentum under drought stress. - Turk. J. Bot. 33: 417-428, 2009b.

Cakmak I., Horst W.J.: Effect of aluminium on lipid peroxidation, superoxide dismutase, catalase, and peroxidase activities in root tips of soybean (Glycine max). - Physiol. Plantarum 83: 463-468, 1991.

Chaves F.J.T., Seraphin S.E.: [Change in osmotic potential and soluble carbohydrates levels in Solanum lycocarpum St.-Hil. in response to water stress]. - Rev. Bras. Bot. 24: 199-204, 2001. [In Portuguese].

Dobrikova A.G., Vladkova R.S., Rashkov G.D. et al.: Effects of exogenous 24-epibrassinolide on the photosynthetic membranes under non-stress conditions. - Plant Physiol. Bioch. 80: 75-82, 2014.

Elstner E.F., Heupel A.: Inhibition of nitrite formation from hydroxylammoniumchloride: A simple assay for superoxide dismutase. - Anal. Biochem. 70: 616-620, 1976.

Fang X.W., Turner N.C., Li F.M. et al.: Caragana korshinskii seedlings maintain positive photosynthesis during short-term, severe drought stress. - Photosynthetica 49: 603-609, 2011.

FAO.: Food and agriculture organization of the United Nation. In: FAO statistical database, 2017 - www.fao.org/statistics/ databases/en/; acessed 11 December 2017.

Fariduddin Q., Yusuf M., Hayat S. et al.: Effect of 28-homobrassinolide on antioxidant capacity and photosynthesis in Brassica juncea plants exposed to different levels of copper. - Environ. Exp. Bot. 66: 418-424, 2009.

Fleta-Soriano E., Munné-Bosch S.: Stress memory and the inevitable effects of drought: a physiological perspective. Front. Plant Sci. 7: 143, 2016.

Flexas J., Ribas-Carbó M., Bota J. et al.: Decreased rubisco activity during water stress is not induced by decreased relative water content but related to conditions of low stomatal conductance and chloroplast $\mathrm{CO}_{2}$ concentration. New Phytol. 172: 73-82, 2006.

Gill M.B., Cai K., Zhang G. et al.: Brassinolide alleviates the drought-induced adverse effects in barley by modulation of enzymatic antioxidants and ultrastructure. - Plant Growth Regul. 82: 447-455, 2017.

Gill S.S., Tuteja N.: Reactive oxygen species and antioxidant machinery in abiotic stress tolerance in crop plants. - Plant Physiol. Bioch. 48: 909-930, 2010.

Gong M., Li Y-J., Chen S-Z.: Abscisic acid-induced thermotolerance in maize seedlings is mediated by calcium and associated with antioxidant systems. - J. Plant Physio. 153: 488-496, 1998.

Hoagland D.R., Arnon D.I.: The Water-Culture Method for Growing Plants without Soil, $2^{\text {nd }}$ ed. Pp. 347. California Agricultural Experiment Station, San Francisco 1950.

Hu W., Yan X., Xiao Y. et al.: 24-epibrassinosteroid alleviate drought-induced inhibition of photosynthesis in Capsicum 
annuиm. - Sci. Hortic.-Amsterdam 150: 232-237, 2013.

Jia L., Liu Z., Chen W. et al.: Hormesis effects induced by cadmium on growth and photosynthetic performance in a hyperaccumulator, Lonicera japonica Thunb. - J. Plant Growth Regul. 34: 13-21, 2015.

Khalid A., Aftab F.: Effect of exogenous application of 24-epibrassinolide on growth, protein contents, and antioxidant enzyme activities of in vitro-grown Solanum tuberosum L. under salt stress. - In Vitro Cell Dev.-P1. 52: 81-91, 2016.

Lawlor D.W., Tezara W.: Causes of decreased photosynthetic rate and metabolic capacity in water-deficient leaf cells: a critical evaluation of mechanisms and integration of processes. Ann. Bot.-London 103: 561-579, 2009.

Li J., Yang P., Gan Y. et al.: Brassinosteroid alleviates chillinginduced oxidative stress in pepper by enhancing antioxidation systems and maintenance of photosystem II. - Acta Physiol. Plant. 37: 222-232, 2015.

Li Y.H., Liu Y.J., Xu X.L. et al.: Effect of 24-epibrassinolide on drought stress-induced changes in Chorispora bungeana. Biol. Plantarum 56: 192-196, 2012.

Lichtenthaler H.K., Buschmann C.: Chlorophylls and carotenoids: Measurement and characterization by UV-VIS spectroscopy. - In: Lichtenthaler H.K., Buschmann C. (ed.): Current Protocols in Food Analytical Chemistry. Pp. 431-438. John Wiley \& Sons, Inc., Hoboken 2001.

Lima J .V., Lobato A.K.S.: Brassinosteroids improve photosystem II efficiency, gas exchange, antioxidant enzymes and growth of cowpea plants exposed to water deficit. - Physiol. Mol. Biol. Plants 23: 59-72, 2017

Liu E.K., Mei X.R., Yan C.R. et al.: Effects of water stress on photosynthetic characteristics, dry matter translocation and WUE in two winter wheat genotypes. - Agr. Water Manage. 167: 75-85, 2016.

Martineau E., Domec J., Bosc A. et al.: The effects of potassium nutrition on water use in field-grown maize (Zea mays L.). Environ. Exp. Bot. 134: 62-71, 2017.

Ma C.C., Gao Y.B., Guo H.Y. et al.: Photosynthesis, transpiration, and water use efficiency of Caragana microphylla, $C$. intermedia, and C. korshinskii. - Photosynthetica 42: 65-70, 2004.

Maxwell K., Johnson G.N.: Chlorophyll fluorescence - a practical guide. - J. Exp. Bot. 51: 659-668, 2000.

Ozkur O., Ozdemir F., Bor M. et al.: Physiochemical and antioxidant responses of the perennial xerophyte Capparis ovata Desf. to drought. - Environ. Exp. Bot. 66: 487-492, 2009.

Rajasekar M., Rabert G.A., Manivannan P.: The effect of triazole induced photosynthetic pigments and biochemical constituents of Zea mays L. (Maize) under drought stress. Appl. Nanosci. 6: 727-735, 2016.

Rivas R., Falcão H.M., Ribeiro R.V. et al.: Drought tolerance in cowpea species is driven by less sensitivity of leaf gas exchange to water deficit and rapid recovery of photosynthesis after rehydration. - S. Afr. J. Bot. 103: 101-107, 2016.

Rochaix J.D.: Regulation of photosynthetic electron transport. Biochim. Biophys. Acta. 1807: 375-383, 2011.

Rutherford A.W., Boussac A.: Water photolysis in biology. Science 303: 1782-1784, 2004.

Scholander P.F., Hammel H.T., Hemmingsen E.A. et al.: Hydrostatic pressure and osmotic potential in leaves of mangroves and some other plants. - P. Natl. Acad. Sci. USA 52: 119-125, 1964

Shao H-B., Chu L-Y., Jaleel C.A. et al.: Water-deficit stressinduced anatomical changes in higher plants. - C. R. Biol. 331: 215-225, 2008.
Silva F.A.S., Azevedo C.A.V.: [Assistat computational program version for the Windows operating system.] - Rev. Bras. Prod. Agroind. 4: 71-78, 2002. [In Portuguese]

Silva E.N., Ribeiro R.V., Ferreira-Silva SL. et al.: Coordinate changes in photosynthesis, sugar accumulation and antioxidative enzymes improve the performance of Jatropha curcas plants under drought stress. - Biomass Bioenerg. 45: 270-279, 2012.

Silveira J.A.G., Araújo S.A.M, Lima J.P.M.S. et al.: Roots and leaves display contrasting osmotic adjustment mechanisms in response to NaCl-salinity in Atriplex nummularia. - Environ. Exp. Bot. 66: 1-8, 2009.

Singh S., Prasad S.M.: Growth, photosynthesis and oxidative responses of Solanum melongena L. seedlings to cadmium stress: mechanism of toxicity amelioration by kinetin. - Sci. Hortic.-Amsterdam 176: 1-10, 2014.

Singh S.K., Reddy K.R.: Regulation of photosynthesis, fluorescence, stomatal conductance and water-use efficiency of cowpea (Vigna unguiculata [L.] Walp.) under drought. - J. Photoch. Photobio. B. 105: 40-50, 2011.

Souza R.P., Machado E.C., Silva J.A.B. et al.: Photosynthetic gas exchange, chlorophyll fluorescence and some associated metabolic changes in cowpea (Vigna unguiculata) during water stress and recovery. - Environ. Exp. Bot. 51: 45-56, 2004.

Steel R.G.D., Torrie J.H., Dickey D.A.: Principles and Procedures of Statistics: a Biometrical Approach, $3^{\text {rd }}$ ed. Pp. 666. Academic Internet Publishers, Moorpark 2006.

Thilakarathna M.S., Raizada M.N.: A meta-analysis of the effectiveness of diverse rhizobia inoculants on soybean traits under field conditions. - Soil Biol. Biochem. 105: 177-196, 2017.

Tukaj Z., Baścik-Remisiewicz A., Skowroński T. et al.: Cadmium effect on the growth, photosynthesis, ultrastructure and phytochelatin content of green microalga Scenedesmus armatus: a study at low and elevated $\mathrm{CO}_{2}$ concentration. Environ. Exp. Bot. 60: 291-299, 2007.

Turner N.C.: Measurement of plant water status by the pressure chamber technique. - Irrig. Sci. 9: 289-308, 1988.

Velikova V., Yordanov I., Edreva A.: Oxidative stress and some antioxidant systems in acid rain-treated bean plants protective role of exogenous polyamines. - Plant Sci. 151: 59-66, 2000.

Vriet C., Russinova E., Reuzeau C.: From squalene to brassinolide: The steroid metabolic and signaling pathways across the plant kingdom. - Mol. Plant 6: 1738-1757, 2013.

Wang Z., Zheng P., Meng J. et al.: Effect of exogenous 24-epibrassinolide on chlorophyll fluorescence, leaf surface morphology and cellular ultrastructure of grape seedlings (Vitis vinifera L.) under water stress. - Acta Physiol. Plant. 37: 1729, 2015.

Wei Z., Li J.: Brassinosteroids regulate root growth, development, and symbiosis. - Mol. Plant 9: 86-100, 2016.

Wu Q.-S., Xia R.-X., Zou Y.-N.: Reactive oxygen metabolism in mycorrhizal and non-mycorrhizal citrus (Poncirus trifoliata) seedlings subjected to water stress. - J. Plant Physio. 163: 1101-1110, 2006.

Wu X., Yao X., Chen J. et al.: Brassinosteroids protect photosynthesis and antioxidant system of eggplant seedlings from high-temperature stress. - Acta Physiol. Plant. 36: 251$261,2014$.

Xia X.-J., Huang L.-F., Zhou Y.-H. et al.: Brassinosteroids promote photosynthesis and growth by enhancing activation of Rubisco and expression of photosynthetic genes in Cucumis sativus. - Planta 230: 1185-1196, 2009.

Yi X.P., Zhang Y.L., Yao H.S. et al.: Rapid recovery of photosynthetic rate following soil water deficit and re- 
watering in cotton plants (Gossypium herbaceum L.) is related to the stability of the photosystems. - J. Plant Physiol. 194: 23-34, 2016.

Yu J.Q., Huang L.F., Hu W.H. et al.: A role for brassinosteroids in the regulation of photosynthesis in Cucumis sativus. - J. Exp. Bot. 55: 1135-1143, 2004.

Yuan G.-F., Jia C.-G., Li Z. et al.: Effect of brassinosteroids on drought resistance and abscisic acid concentration in tomato under water stress. - Sci. Hortic.-Amsterdam 126: 103-108, 2010.

Yuan X.K., Yang Z.Q., Li Y.X. et al.: Effects of different levels of water stress on leaf photosynthetic characteristics and antioxidant enzyme activities of greenhouse tomato. -
Photosynthetica 54: 28-39, 2016.

Zhang C., Zhan D.X., Luo H.H. et al.: Photorespiration and photoinhibition in the bracts of cotton under water stress. Photosynthetica 54: 12-18, 2016.

Zhang M., Zhai Z., Tian X. et al.: Brassinolide alleviated the adverse effect of water deficits on photosynthesis and the antioxidant of soybean (Glycine $\max$ L.). - Plant Growth Regul. 56: 257-264, 2008.

Zhang Y., Xu S., Yang S. et al.: Salicylic acid alleviates cadmium-induced inhibition of growth and photosynthesis through upregulating antioxidant defense system in two melon cultivars (Cucumis melo L.). - Protoplasma 252: 911924, 2015.

(C) The authors. This is an open access article distributed under the terms of the Creative Commons BY-NC-ND Licence. 